Vegetatio 91: 3-13, 1991.

A. Henderson-Sellers and A. J. Pitman (eds).

Vegetation and climate interactions in semi-arid regions.

(C) 1991 Kluwer Academic Publishers. Printed in Belgium.

\title{
Desertification and global change
}

\author{
M. M. Verstraete' \& S. A. Schwartz ${ }^{2}$ \\ 'Institute for Remote Sensing Applications, CEC Joint Research Centre, Ispra Establishment, TP 440, \\ I-21020 Ispra (Varese), Italy; ${ }^{2}$ Department of Atmospheric, Oceanic and Space Sciences, The University \\ of Michigan, Ann Arbor, MI 48109-2143, USA
}

Accepted 24.8.1990

\begin{abstract}
Arid and semiarid regions cover one third of the continental areas on Earth. These regions are very sensitive to a variety of physical, chemical and biological degradation processes collectively called desertification. Although interest in desertification has varied widely in time, there is a renewed concern about the evolution of dryland ecosystems because (1) a significant fraction of existing drylands already suffers from miscellaneous degradation processes, (2) increasing populations will inevitably result in further over-utilization of the remaining productive areas, (3) climatic changes expected from the greenhouse warming might result in drier continental interiors, and (4) some of the desertification processes themselves may amplify local or regional climatic changes. This paper reviews some of the many aspects of this issue in the context of the Global Change research program.
\end{abstract}

\section{Introduction}

Humanity has had a long association with arid and semiarid regions: the first great civilizations (in Egypt and Mesopotamia) developed at the end of the climatic optimum some 3000 years B.C., at a time when the Sahara appears to have been vegetated as parts of the Sahel are today (Butzer 1966; Lamb 1977). By the time the Great Pyramids were erected in Egypt (around 2700 B.C.), the climate of Northeast Africa and the Middle East was in a drying phase that resulted in the arid landscapes we have known for much of the last 5000 years (El-Baz 1983). Superimposed on this long term climatic evolution, however, is the increasingly large impact of growing human populations. The expansion into new territories, and exploitation of the natural resources of these drylands beyond their carrying capacity has resulted in rapidly deteriorating environmental conditions.
This degradation now affects many or most ecosystems on this planet, and there is a progressive awareness by the public and the decision makers of the many aspects of this land abuse (destruction of tropical rain forests, various forms of pollution, including toxic and nuclear wastes, sewage, acid deposition, etc., the so-called 'ozone-hole', oils spills and chemical or nuclear accidents, to name but a few). The release into the atmosphere of large quantities of carbon dioxide, methane and other pollutants by industrial and agricultural activities is now so large that the composition of the atmosphere is affected, and that in turn is expected to affect the climate of the Earth (Henderson-Sellers \& Blong 1989; Schneider 1989).

In response to this increased awareness, the scientific community has started to design and implement a coordinated research effort geared at documenting the current state and probable evo- 
lution of the global system. The International Geosphere Biosphere Program (IGBP) is an interdisciplinary research effort 'to describe and understand the interactive physical, chemical, and biological processes that regulate the total Earth system, the unique environment that it provides for life, the changes that are occurring in this system, and the manner in which they are influenced by human actions' (NAS 1988, p. 2). This ambitious project is coordinated by the International Council of Scientific Unions (ICSU). The expression 'Global Change' is often used as a synonym to IGBP research program, it also designates the US component of the IGBP. In this paper, we review the nature, extent and severity of desertification, and discuss possible interactions between this form of land degradation and the expected climate and environmental changes. The specific contributions of in situ observations and satellite remote sensing systems in the overall strategy to monitor global environmental degradation are described in a companion paper (Verstraete \& Pinty 1990).

\section{The concept of desertification}

Much time and effort has been spent trying to define the concept of desertification. Such a task is difficult, if not impossible, because of the number and complexity of the issues involved, the interdisciplinary nature of the problem, and the range of spatial and temporal scales over which this concept is applied (Verstraete 1983, 1986). For the present purpose, we shall define desertification as the set of all environmental degradation processes in hot drylands (hyperarid, arid, semiarid and subhumid regions), as a result of either climatic stress or human mismanagement, or both. Desertification will also include the causes (to the extent these can be identified) and the impact of degradation on natural and managed ecosystems. Clearly, environmental degradation can occur in all biomes, but the fragile nature, harsh climate and expanding area of these drylands have made it a primary focus of attention. Desertification usually has severe long term consequences for the productivity of the land, and therefore for the populations that inhabit these regions.

The word 'desertification' was first introduced by the French forester Aubréville in his book

Table 1. Extent of drylands by geographical region.

\begin{tabular}{llrrrrr}
\hline [km $\left.{ }^{2}, \%\right]$ & Total & Hyperarid & \multicolumn{1}{l}{ Arid } & Semiarid & Subhumid & Dryland \\
\hline Africa & $30,321,130$ & $6,094,094$ & $6,169,507$ & $5,129,749$ & $4,051,032$ & $21,444,382$ \\
& & 20.10 & 20.35 & 16.92 & 13.36 & 70.72 \\
America & $42,567,895$ & 164,582 & $2,099,881$ & $4,679,068$ & $4,327,944$ & $11,271,475$ \\
& & 0.39 & 4.93 & 10.99 & 10.17 & 26.48 \\
Middle East & $6,139,098$ & $1,125,997$ & $3,052,996$ & 985,490 & 769,062 & $5,933,545$ \\
& & 18.34 & 49.73 & 16.05 & 12.53 & 96.65 \\
Asia & $38,120,322$ & 382,439 & $4,008,463$ & $5,312,779$ & $3,925,704$ & $13,629,385$ \\
& & 1.00 & 10.52 & 13.94 & 10.30 & 35.75 \\
Australia & $7,686,884$ & & $3,766,572$ & $1,537,377$ & $1,229,900$ & $6,533,850$ \\
& & & 49.00 & 20.00 & 16.00 & 85.00 \\
Europe & $10,507,630$ & & 10,096 & 239,179 & 267,503 & 516,778 \\
& & & 0.10 & 2.28 & 2.55 & 4.92 \\
\hline Grand total & $135,897,300$ & $7,767,112$ & $19,107,518$ & $17,883,642$ & $14,571,146$ & $59,329,417$ \\
& & 5.72 & 14.06 & 13.16 & 10.72 & 43.66 \\
\hline
\end{tabular}

Sources of raw data: (Rogers 1981) and Hammond (1985). 
Climats, Forêts, et Désertification de l'Afrique Tropicale (Aubréville 1949). He witnessed the degradation and disappearance of tropical forests in many humid and sub-humid parts of Africa, and attributed it to a large extent to the slash and burn agricultural practices of the local populations. This destruction of the forest lead to savannas with scattered trees, and then further to soil erosion and a general tendency towards more xeric environmental conditions (Dregne 1986, p. 6). Aubréville had identified climate change as a potential factor, but could not estimate its importance for lack of adequate data. It is only later on that the concept became commonly associated with arid and semiarid regions.

Hot drylands are characterized by high solar radiation, potential evapotranspiration rates, and diurnal ranges of temperature, and low precipitation and atmospheric humidity. The location and extent of these regions depends strongly on how they are defined, and many definitions have been proposed in the literature. Table 1 shows the extent of hyperarid, arid, semiarid and subhumid areas for six regions of the world. The data were compiled from information given by Rogers (1981), who digitized UNESCO's map showing the World Distribution of Arid Regions (UNESCO 1977). This map was constructed on the basis of hydrological data, using a water balance approach; it arguably represents the best map of aridity currently available.

It can be seen that almost $33 \%$ of the continents are hyperarid, arid or semiarid, and that almost $44 \%$ of all continental areas (excluding Antarctica) can be classified as drylands. While degradation in hyperarid regions is limited to

Table 2. Distribution of desertified areas by economic activity.

\begin{tabular}{lrl}
\hline Economic use & Area $\left[\mathrm{km}^{2}\right]$ & $\%$ desertified \\
\hline Rangeland & $25,560,000$ & 62 \\
Rainfed agriculture & $5,700,000$ & 60 \\
Irrigated agriculture & $1,310,000$ & 30 \\
Total productive drylands & $32,570,000$ & 61 \\
\hline
\end{tabular}

Source: WRI, 1986, p. 278. oases (Meckelein 1980), much of the arid, semiarid and subhumid areas are generally considered to be a risk of desertification.

Table 2 shows the distribution of productive drylands, broken down by type of economic activity, as well as the percentage thought to be desertified as of the early eighties. These data are not directly comparable to those of Table 1 , but it is interesting to note that rangelands are by far the largest areas affected by desertification.

In the late seventies, the United Nations estimated the rate of desertification at between 54000 and $58000 \mathrm{~km}^{2}$ (UNCOD 1977, p. 9; United Nations, 1978, p. 2). By 1984, Norman Myers estimated that some $120000 \mathrm{~km}^{2}$ of agricultural and pastoral land were deteriorating beyond useful economic use per year (Myers 1984, p. 46). These numbers should be compared to estimates of deforestation worldwide, which range from 100000 to $113000 \mathrm{~km}^{2}$ per year, with the bulk of the destruction occurring in the tropics (Myers 1984 , p. 42; WRI 1986, p. 72).

Arid lands are dynamic regions, they have been evolving over thousands of years, mostly in response to climatic changes (Warren 1984). Throughout most of its history, humanity has been able to cope with such an evolution (and with its own degradation of the environment) by colonizing new and hitherto unaffected areas. Only during the last century has it become apparent that the land resource was finite; and individuals and societies are only now becoming aware of the consequences of unlimited growth and careless abuse of finite natural resources. Recurrent severe droughts in the Sahel and more recently in Ethiopia, have helped to periodically focus attention on this problem, although the degradation occurs in many other regions.

Drylands often experience significant interseasonal and inter-annual climate variability, and in particular periods of reduced water availability. Drought therefore constitutes a 'normal', expected (if largely unpredictable) component of their climate: it is a temporary situation where the amount of available water is smaller than what would be needed for the intented economic use, or for the normal growth and development of the 
plant cover (Gibbs 1975, p. 11). Droughts have been identified both on the basis of meteorological or hydrological parameters alone (see Landsberg 1975 , for a review), or by reference to economic impacts, or even perceptions of risk (Heathcote 1969). Many authors view drought as a shortlived phenomenon responsible for recurrent but not permanent stress to the environment (e.g., Le Houérou 1977). This approach, although understandable a posteriori, may not be operational because it is impossible to know how long a dry spell is going to last. The Sahel is a case in point, where the relatively dry period that started around 1968 was long identified as a drought, even though is has not ended yet, more than 20 years later (Nicholson 1989). How long does a drought need to be before it is called a climatic shift or change?

Desertification is generally conceived as a much wider concept than drought, involving not only water availability issues, but also various forms of soil degradation, loss of biological productivity, and a host of human impacts. It is deemed to occur on 'long' time scales, causing a slow but cumulative decline in biological productivity and in the capability of the land to support its natural vegetation or agricultural exploitations. Desertification must be distinguished from drought, but since the end of a drought even cannot be predicted, its duration can only be known after the fact, and the distinction between desertification and drought in terms of their respective duration cannot be applied operationally. The combination of progressive desertification and droughts can be severely crippling to the environment, as the stress created by human overexploitation of the land becomes especially visible during severe droughts. Drought and desertification can amplify each other's impacts, and the resulting degradation of the environment can further affect adjacent areas, either directly (invading sand dunes, siltation of dams downstream), or indirectly (migration of populations, increased international tensions over increasingly scarce resources).

The intensity of desertification processes can range from slight to very severe in terms of the degradation of plant and soil resources (Dregne 1986). Desertification threatens many of the arid and semiarid regions of the world, and involves a large number of complex interactions between physical, topographical, edaphic, and biological parameters, as well as human components (land use and ownership, social structures, economic development, and health status) (Spooner 1982). Different processes and interactions take place in different ecosystems, but the general tendency towards degradation that results from the interplay of these processes and interactions is common to all situations. In that sense, desertification, which has been called the cancer of drylands, can affect any area which has been made vulnerable enough by climatic stress or human overexploitation, or both.

It is difficult to estimate the number of people affected by desertification because geographical, political and economic differences whithin each country result in some population classes being more affected or more at risk than others. Nevertheless, it is probable that around 100 million people are directly affected by desertification today, and that another 900 million may be at risk now or in the near future (UNCOD 1977, p. 8; United Nations 1978, p. 2; Paylore \& Greenwell 1980, p. 14-18; Paylore 1984, p. 18-19; AlSudeary 1988, p. 13).

\section{The processes of land degradation}

Desertification often results from the degradation of the vegetation cover by overgrazing, overtrampling, wood collection, repeated burning, or inappropriate agricultural practices. It leads to a general decrease in productivity of the land and in the accelerated degradation of the soil resource due to soil erosion (both by wind and water), siltation, salinization and alkalinization of irrigated lands, or dry salting. The excessive loss of soil, nutrients, and sometimes even seeds from the ecosystem affects the capability of the vegetation to recover and constitutes the principal mechanism of irreversible damage to the environment.

The impact of grazing on pastoral rangelands 
depends largely on its intensity and timing. Light grazing may increase the productivity of the range by stimulating new growth, while moderate to heavy grazing often results in the preferential removal of the more palatable species (Warren \& Maizels 1977, p. 203-210). This facilitates the invasion of less palatable or inedible species (invaders) by modifying the ecological niches. Overgrazing during the dry season further reduces the vegetation cover and increases the risk of soil erosion. Perennial species are particularly important in stabilizing the soil, especially during the dry season, while ephemeral and annual species may help control soil erosion during the wet season.

The deterioration of the soil surface, which results from the removal of the vegetation cover, strongly affects the health, vigor and reproductive capacity of the remaining plants through the disruption of plant-water relations. Subsequently, there is an increase in runoff, sheet and gully erosion on sloping ground; the top soil is lost, together with its store of water, nutrients, and seeds. Compounding the problem is the higher bulk density of the soil caused by severe trampling, which decreases infiltration by water and also increases runoff. Ultimately, if erosion is not stopped, it will completely destroy the productive value of the land by soil stripping and gully extension.

Rainfed farming practices have their own distinctive signatures of desertification. The problem often originates on land cleared for cultivation or left fallow. As soon as the natural vegetation is cleared, the soil is made vulnerable to accelerated wind and water erosion. The introduction of agricultural equipment, designed for the deep soils of mid-latitude regions, into tropical regions with thin soils can further aggravate the soil loss (soil pulverization and removal of humus and nutrients). The removal of the plant cover during harvests results in bare soils and promotes the formation of a hard crust at the surface. This crusting of the soil reduces infiltration and increases runoff. Thus, as in pastoral rangelands, the fertile surface soil is stripped away, leaving behind infertile subsoils. Gullies may then form on lower parts of slopes, presenting similar physical obstacles to farming operations as they do to rangeland practices. In addition, runoff from the slopes causes sedimentation downhill; waterways and dams are filled, and flooding is intensified in low-lying areas (UNCOD 1977). The degradation processes act synergistically in both rainfed farming and pastoral systems.

Soil erosion by wind and water may take place in both arid and semiarid regions, and at various times during the year (Verstraete \& van Ypersele 1986). The impact of wind erosion clearly dominates in the drier regions, while water erosion will affect mostly the wetter areas (Marshall 1973, p. 58). Furthermore, it is the extreme events which are the most destructive, especially if they occur in the dry season, a period of maximum sensitivity to perturbation. The risk of soil erosion depends on both the susceptibility of the soil to erosion, and on the probability of a meteorological event (wind gust or rainfall) of sufficient magnitude to displace the soil. For example, the erodibility of the soil may be highest during the dry season, when the protective vegetation cover is minimal, but the probability of intense rains is highest during the rainy season. The highest risk of water erosion therefore occurs at the end of the dry season, when the plant cover has not grown back yet, but the likelihood of an intense rainfall increases.

Wind erosion affects the soil structure and composition in different ways. First, the flow of particles is proportional to the cube of the friction wind speed above a threshold value (Bagnold 1943; Gillette et al. 1982; Skidmore 1986). Second, the coarser sandy materials drift over short distances (a few hundreds of meters to a few kilometers), while the finer materials are carried away in the wind, sometimes over continental distances: Dust from the Sahara has been observed to cross the Atlantic Ocean, and 'sand rains' have been reported from as far as Northern Europe and the Caribbeans (Carlson \& Prospero 1972; Rapp 1974; MacLeod et al. 1977; Morales 1979).

The fine top soil which is lost to wind erosion is the most fertile portion of the soil complex and 
only sterile soil is left behind (UNCOD 1977). The lack of water in these shallow soils also prevents seedlings from surviving prolonged droughts, making permanent plant life even more difficult. When perennial seedlings do manage to emerge, they may easily be uprooted and blown away. With little protection left on the ground, the blasting impact of moving sand can destroy young crops (Le Houérou 1977).

Water erosion is intimately linked to the hydrological cycle of arid and semiarid lands. The primary physical agent of erosion is the transfer of kinetic energy from the raindrops to the soil particles. Once these particles have been dislodged, they can be transported away by surface runoff. The presence of vegetation greatly decreases the impact of raindrops because the leaves absorb much of their momentum: the drops break up and slow down considerably. The sparser the vegetation cover, the more rainfall reaches the ground, where it must either percolate into the ground or runoff.

Soils are extremely variable in their spatial distribution. The most important characteristics of soils are their texture, structure and chemical composition, as well as their depth. Soil texture is determined on the basis of the relative fractions of sand, silt, and clay. Runoff from a specific soil depends primarily on the intensity of precipitation, the infiltration rate and the local slope. The coarser soils (i.e., with an important sand fraction), have a high infiltration rate and can therefore absorb intense showers. Soils with a major clay fraction have a much reduced infiltration rate, and tend to generate more runoff, even under lower precipitation intensities (Hillel 1982). The breakup of soil aggregates by large raindrops may lead to the dispersal of the fine elements and the sealing of the surface when the soil dries up. This crusting contributes to the formation of an impermeable surface (Le Houérou 1977). Soil depth plays a crucial role because it directly affects the water storage capacity, and the amount of nutrients (both mineral and organic) available for plant growth and development. The hydraulic conductivity of soils is a non-linear function of the water content, with much lower values for drier soils. The drying of the top soil impedes water movement and may therefore reduce the total evaporation. Deep soils have a better chance of conserving moisture than shallow soils.

Since water availability is the primary limiting factor for plant productivity in dry regions, irrigation has often been seen as the best way to boost production. This technique, however, presents its own set of problems and can also lead to the permanent degradation of the land. The productivity of the vegetation is directly linked to its transpiration rate; therefore the goal of irrigation is to provide plants with just enough water in the soil. Excess water should be drained. When this is not done, irrigation water infiltrates the soil and picks up soluble salts. The drying of the top soil creates a gradient of moisture and generates a slow but continuous upward flow of mildly salty water. These salts therefore accumulate at the surface as the water evaporates. Most plants cannot tolerate very high salt concentrations in the upper soil, as it affects their capability to absorb water in the root layer. Ultimately, crops must be switched to halophytes (salt tolerant plants) or the field must be abandoned. On the other hand, proper irrigation and drainage may be designed to flush the salts in the upper soil layers, but this requires high capital investments and constant maintenance of the drainage system.

Last but not least, fire has long been recognized as a potentially destructive agent. It is well known that a light fire may actually stimulate new plant growth, especially in grasslands, and accelerate the turnover of nutrients in the environment. Burning may also help control some bush or tree invasion, but there are many possible negative effects. Hot fires can sterilize the ground by destroying the nitrogen-fixing bacteria, thereby reducing the productivity of the land, especially if they are ill-timed. Hot fires can lead to the destruction of humus and a loss of fertility, a destabilization of the water relations in the topsoil, or even the loss of the seedstore (UNCOD 1977). Even light fires can take their toll by causing distillates of organic matter to coat particles of the soil surface, decreasing infiltration and increasing runoff or erosion vulnerability 


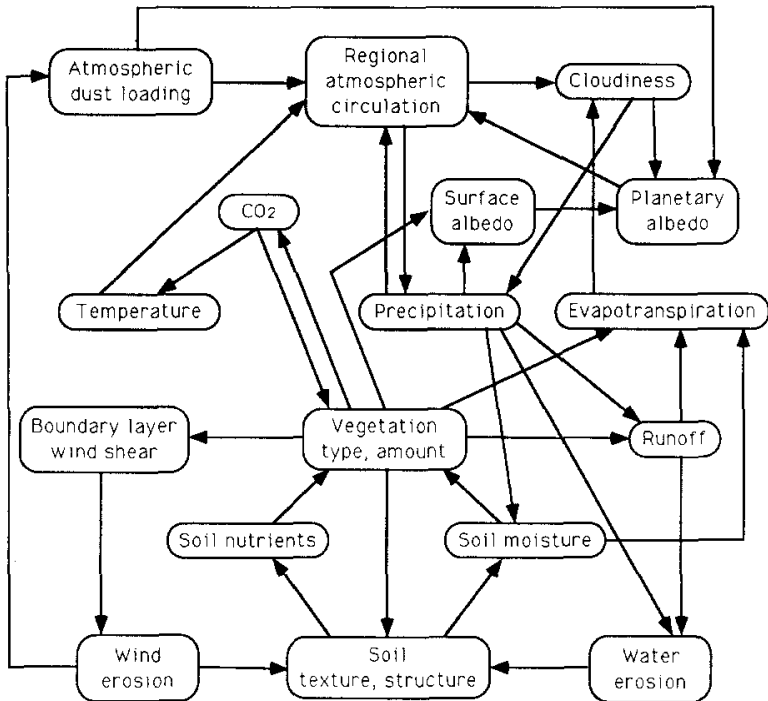

Fig. 1. Soil, vegetation and atmosphere interactions within the context of desertification.

(Warren \& Maizels 1977). Fires can drastically modify the geophysical environment near the surface: the albedo may be affected, at least spectrally, the roughness of the surface may be changed in either direction, depending on the type and density of the cover, and hydrological relations at the surface may be modified.

The interactions between the components of the environment (soil, plants, climate) are shown shematically in Figure 1. This diagram is not intended to be exhaustive, or to describe the particular situation at a specific site; but it does attempt to show how various aspects of a dryland ecosystem depend on each other and are affected, directly or indirectly, by biogeophysical processes that take place in this environment. One of the major difficulties of modeling these interactions results from the fact that they take place at many different spatial and temporal scales (Avissar \& Verstraete 1990).

This description of desertification would not be complete without a discussion of human aspects, both as causes of degradation and as victims of its impact. Societies directly affect the environment through such activities as pastoralism, agriculture, transportation, urbanization and industrialization. These activities are largely controlled by the interplay between economic constraints and the availability of natural resources, as well as by the expectations of individuals and other cultural factors. Progress in medicine and the provision of medical services has improved the quality of life and decreased mortality rates, at least for those segments of the population that have access to these services. On the other hand, environmental degradation and the breakdown in the production systems from desertification is often accompanied by a lowering of health standards, a decrease in nutritional intake, and an increase in morbidity. The health status of a population and the location and accessibility of natural resources, in turn, directly influence the rates of migration of populations. Hence, a region may be indirectly affected by desertification in a neighboring area. On a larger political scale, these problems can result in severe internal problems between social classes, or even in massive environmental migrations, possibly causing international tensions. There is an extensive literature on this subject. The interested reader should refer to Copans (1975), UNCOD (1977), Spooner (1982) and Glantz (1987) for introductions to this vast subject.

\section{Climate and environmental change}

Climate variability, and in particular extreme conditions, must be expected in drylands. What is more worrisome, however, is the possibility that human activities may be responsible for significant further climatic changes in the foreseeable future. The primary cause for concern lies with the observed change in the chemical composition of the atmosphere. Agricultural, industrial and urban activities, and specifically the heavy consumption of fossil fuels, result in the injection of large quantities of carbon dioxide and many other pollutants in the lower atmosphere. Some of these compounds find their way into the oceans or may be re-absorbed by the surface, but a large fraction remains airborne and contributes to the trapping of thermal infrared radiation emitted by the surface. This so-called greenhouse effect results in a substantial heating of the air near the ground. 
It is currently estimated that the concentration of $\mathrm{CO}_{2}$ in the atmosphere could reach twice its pre-industrial value in the first half of the next century. Many atmospheric scientists have attempted to evaluate the likely temperature change that would result, using general circulation models of the atmosphere. Different models predict somewhat different distributions of heating because of internal differences in their representation of the physics and dynamics of the atmosphere (Schlesinger 1989), but results from these numerical sensitivity studies show that the globally-averaged annual mean surface temperature could increase by 2 to $6^{\circ} \mathrm{C}$ by 2050 . Furthermore, these expected changes in temperature will likely be associated with major perturbations of the hydrological cycle. The actual impact on the water cycle is difficult to assess, but it is quite possible that the interior of large continents may experience further drying (Kellogg \& Zhao 1988).

Furthermore, the impact of changes at the surface on the climate itself must also be considered. Focusing on land areas, the climate is affected by the underlying surface in three major ways: first, the optical properties of the surface, in particular albedo, control the rate of solar energy absorption by the climate system. Second, the vegetation cover affects the rates of transfer of energy, water and various chemical compounds between the surface and the atmosphere. And third, the roughness of the surface controls the exchange of momentum between the atmosphere and the planet, and strongly affects the divergence of the wind fields in the atmospheric boundary layer (Verstraete \& Dickinson 1986; Nicholson 1988).

The concern for global change goes far beyond just climatic change, however. The study of the cycling of major biogeochemicals among the various components of the climate system has provided a new paradigm for global investigations. Arid and semiarid regions have long been considered wastelands, but they are now recognized as integral parts of the Earth system. Detailed investigations in the southwest United States showed that grazing can increase heterogeneities in the spatial and temporal distribution of water, nitrogen, and other soil resources. Biogeochemi- cal cycles provide a new convenient framework to understand the invasion of desert shrubs and the progressive degradation of the environment, and to try to predict the likely future evolution of these areas as well as the interactions between arid lands and other ecosystems (Schlesinger et al. 1990).

It is important to appreciate the significance of the climatic changes described above. First of all, local and regional temperature or moisture changes may be much higher (or lower) than these global values. Some regions will likely be more affected than others. Second, a slight change in mean values also results in more frequent extreme conditions, even without a change in the statistical distribution of the climatic parameters. Third, a change of global mean temperature of this magnitude in such a short amount of time is essentially unprecedented: even the warming responsible for the deglaciation 15000 years ago was ten times slower. As a result, there is some concern about the capability of the biosphere to cope with such a change.

\section{Scientific issues}

The bottom line is therefore relatively clear: the human population is growing at the rate of 95 million individuals per year (or about 11000 per hour) (Ehrlich and Ehrlich, 1990, p. 9), and desertification alone accounts for the loss of $120000 \mathrm{~km}^{2}$ of productive land per year (about 1400 ha per hour). Since we also loose at least $120000 \mathrm{~km}^{2}$ of forests and 24 to 26 billion tonnes of top soil per year through erosion (Ehrlich \& Ehrlich 1990, p. 28), it is not difficult to see that this situation cannot be sustained for much longer. The time is for action, not panic, and the scientific community has a definite role to play.

First of all, it is urgent to clearly assess the situation and establish the probable future evolution. In fact, the lack of precise information about the extent and severity of the population-environment-climate problem has consistently been recognized over the last 40 years. Here are a few selected quotes from the literature on this subject: Aubréville (1949), p. 330: 
A few years ago, we studied this problem of desertification of West Africa along the Saharan border without reaching definite conclusions. We were not able to demonstrate a progressive drying of the climate because meteorological observations and statistics were not reliable enough and did not cover long enough periods. [Translated from French by M. Verstraete]

McGinnies et al. (1968), p. 3:

'To the extent that we have experienced widespread desert encroachment within historic times, we are far from unanimous as to its causes. [...] For the immediate future lack of basic data about desert environments remains our largest single category of arid-lands problem.'

Warren and Maizels (1977), p. 177 and 186:

'This chapter briefly reviews the evidence for desertification. It will soon become apparent that this is not an easy task. Statistics are seldom in the right form, and are hard to come by, and even harder to believe, let alone interpret. [...] The evidence for desertification is diffuse and almost impossible to quantify.'

Bie (1989), p. 2:

'Although the occurrence, if not the severity, of famines is well documented, there is a scarcity of data linking general dryland degradation to famine. There is little doubt, however, that local land degradation has taken place. There is therefore a need to develop better methods whereby land degradation can be assessed. Inaccurate methodologies appear in the past to have had major impact on donor attitudes on the occurrence, frequency and severity of dryland degradation.'

Monitoring the environment (in drylands as well as other ecosystems) plays a number of crucial roles and must be pursued to (1) establish a baseline against which future observations can be compared, (2) document the spatial and temporal variability of the relevant environmental parameters, (3) identify the regions at risk of further degradation, and the nature of the processes at work, (4) provide the data needed to build and validate the mathematical models of the environment that are needed to understand and predict the evolution of these ecosystems, (5) support policy decision making in such tasks as prioritizing the target areas for relief and conducting costbenefit analyses of various remedial actions or feasibility studies, as well as support field activities geared towards minimizing further degradation or reclaiming affected areas, and (6) evaluate the effectiveness of these policies, plans and remedial actions.

It is unfortunately not clear where desertification is the most severe, or at what rate it is occurring. Preventive measures or remedial actions should be based on a accurate assessment of the situation, and that crucial element is still missing. While there are countless reports of impending disasters at the local scale, there is no coherent way to obtain a synthetic accurate and quantitative view of the global situation. Satellite remote sensing techniques appear to be the most appropriate for this task, but a lot more work must be done in order to retrieve quantitative information from these data, as opposed to qualititative estimates. A discussion of the potential contribution of space platforms, along with traditional in situ measurement techniques, can be found in a companion paper (Verstraete \& Pinty 1990).

In parallel to this effort, the second contribution of the scientific community must be a better understanding of the processes involved and an analysis of the implications of the remedial actions that may be envisaged. The global models used to investigate the scenarios described above and their impacts represent the state of the art in climate modeling, even though they still suffer from significant shortcomings. For example, in most cases, the representation of the oceans and of air-sea interactions are rather crude, and the parameterization of cloud and surface processes cannot do justice to the number and complexity of the processes that actually take place. These models must be expanded to include the most significant biogeochemical cycles. In fact, a hierarchical set of models at various scales must be designed to study and understand better the interactions between physical, chemical, biological, and human processes. This will require further emphasis on interdisciplinary investigations, 
as well as a renewed effort to train generations of young scientists to deal effectively with this complex system. The Global Change Research Program is a major step forward in that direction.

\section{Acknowledgments}

The Department of Atmospheric, Oceanic and Space Sciences of the University of Michigan and the School of Earth Sciences of Macquarie University financed the participation of the first author to the 'Conference on Degradation of Vegetation in Semi-Arid Regions: Climate Impact and Implications', Macquarie University, January 29-31, 1990. The support and encouragements of Prof. W. Kuhn and A. HendersonSellers are gratefully acknowledged. Serena Schwartz is grateful to the Population-Environment Dynamics Program administred by the School of Public Health of the University of Michigan for financial support of her interdisciplinary studies.

\section{References}

Al-Sudeary, A. M. 1988. Alleviation of rural poverty in arid lands. In: Arid Lands: Today and Tomorrow. Edited by E. Whitehead, C. Hutchinson, B. Timmermann and R. Varady, Westview Press, Boulder, 13-20.

Aubréville, A. 1949. Climats, Forêts, et Désertification de l'Afrique Tropicale. Société d'Editions Géographiques, Maritimes et Tropicales, Paris, $351 \mathrm{pp}$.

Avissar, R. \& Verstraete, M. M. 1990. The representation of continental surface processes in mesoscale atmospheric models. Reviews of Geophysics 28: 35-52.

Bagnold, R. A. 1943. The Physics of Blown Sand and Desert Dunes. William Morrow \& Co., New York.

Bie, S. W. 1989. Dryland degradation assessment techniques. Outline of a presentation for Session 1 of the Professional Development Workshop on Dryland Management, The World Bank, Washington DC, May 10-11, 1989.

Butzer, K. W. 1966. Climatic changes in the arid zones of Africa during early to mid-Holocene times, in World Climate from 8000 to $0 \mathrm{BC}$. Proceedings of the International Symposium held at Imperial College, London, 18 and 19 April 1966. Royal Meteorological Society, 72-83.

Carlson, T. N. \& Prospero, J. M. 1972. The large-scale move- ment of Saharan air outbreaks over the northern Equatorial Atlantic. Journal of Applied Meteorology 11: 283-297.

Copans, J. 1975. Sécheresses et Famines du Sahel, Volumes I and II. F. Maspéro, Paris, 150 pp. and 144 pp.

Dregne, H. 1986. Desertification of arid lands. In: Physics of Desertification, Edited by F. El-Baz and M. Hassan, Martinus Nijhoff Publishers, Dordrecht, 4-34.

Ehrlich, P. R. \& Ehrlich, A. E. 1990. The Population Explosion. Simon and Schuster, New York, 320 pp.

El-Baz, F. 1983. A geological perspective of the desert. In: S. Wells and D. Haragan (Eds.), Origin and Evolution of Deserts. University of New Mexico Press, Albuquerque, 163-183.

Gibbs, W. J. 1975. Drought: Its definition, delineation and effects, in Drought: Lectures presented at the 26th session of the WMO Executive Committee, Special Environmental Report No. 5, WMO No. 403, Geneva, 1-39.

Gillette, D. A., Adams, J., Muhs, D. \& Kihl, R. 1982. Threshold friction velocities and rupture moduli for crusted desert soils for the input of soil particles into the air. J. Geophys. Res. 87: 9003-9015.

Glantz, M. H. (Editor) 1987. Drought and Hunger in Africa: Denying Famine a Future. Cambridge University Press, Cambridge, $457 \mathrm{pp}$.

Hammond 1985. Ambassador World Atlas. Hammond Inc., $484 \mathrm{pp}$.

Heathcote, R. L. 1969. Drought in Australia: A problem of perception. The Geographical Review 59: 175-194.

Henderson-Sellers, A. \& Blong, R. 1989. The Greenhouse Effect: Living in a Warmer Australia. New South Wales University Press, Kensington, $211 \mathrm{pp}$.

Hillel, D. 1982. Introduction to Soil Physics. Academic Press, New York, 365 pp.

Kellogg, W. W. \& Zhao, Z. 1988. Sensitivity of soil moisture to doubling of carbon dioxide in climate model experiments. Part 1: North America, Journal of Climate 1: 348-366.

Lamb, H. H. 1977. Climate: Present, Past and Future, Vol. 2, Climatic History and the Future. Methuen and Co., London, 835 pp.

Landsberg, H. E. 1975. Drought: A recurrent element of climate. In: Drought: Lectures presented at the 26th session of the WMO Executive Committee, Special Environmental Report No. 5. WMO No.403, Geneva, 41-90.

Le Houérou, H. N. 1977. The nature and causes of desertization. In: Desertification. Edited by M. Glantz, Westview Press, Boulder, 16-38.

MacLeod, N. H., Schubert, J. S. \& Ananejionu, P. 1977. Report on the Sahel 4 African Drought and Arid Lands Experiment. In: Skylab Explores the Earth, NASA, Washington DC, 263-286.

Marshall, J. K. 1973. Drought, land-use and soil erosion. In: The Environmental, Economic and Social Significance of Drought. Edited by J. V. Lovett, Angus and Robertson Publishers, Sydney, 55-77. 
McGinnies, W., Goldman, B. \& Paylore, P. (Editors) 1968. Deserts of the World: An Appraisal of Research Into Their Physical and Biological Environments. University of Arizona Press, Tucson, 788 pp.

Meckelein, W. (Editor) 1980. Desertification in Extremely Arid Environments. Stuttgarter Geographische Studien, Band 95, Stuttgart University, $203 \mathrm{pp}$.

Morales, H. C. (Editor) 1979. Saharan Dust: Mobilization, Transport, Deposition. SCOPE Report 14, Wiley and Sons, Chichester.

Myers, N. (Editor) 1984. Gaia: An Atlas of Planet Management. Anchor Press, Garden City, 272 pp.

NAS 1988. Towards an Understanding of Global Change: Initial Priorities for U.S. Contributions to the IGBP. National Academy Press, Washington DC, $213 \mathrm{pp}$.

Nicholson, S. E. 1988. Land surface atmosphere interaction: Physical processes and surface changes and their impact. Progress in Physical Geography 12: 36-65.

Nicholson, S. E. 1989. Long-term changes in African rainfall. Weather 44: 46-56.

Paylore, P. 1984. One of us must be wrong: Fools rush in; Part 4. Arid Lands Newsletter 21: 18-19.

Paylore, P. \& Greenwell, J. R. 1980. Fools rush in; Part 2: Selected arid lands population data. Arid Lands Newsletter 12: 14-18.

Rapp, A. 1974. A review of desertization in Africa: Water, vegetation and man, SIES Report No. 1, Secretariat for International Ecology, Stockholm, Sweden, $77 \mathrm{pp}$.

Rogers, J. A. 1981. Fools rush in, Part 3: Selected dryland areas of the world. Arid Lands Newsletter 14: 24-25.

Schlesinger, M. E. 1989. Model projections of the climatic changes induced by increased atmospheric $\mathrm{CO}_{2}$. In: Climate and the Geo-Sciences: A Challenge for Science and Society in the 21 st Century. Edited by A. Berger, S. Schneider and J. Cl. Duplessy. Kluwer Academic Publishers, 375-415.

Schlesinger, W. H., Reynolds, J. R., Cunningham, G. L., Huenneke, L. F., Jarrel, W. M., Virginia, R. A. \& Withford, W. G. 1990. Biological feedbacks in global desertification. Science 247: 1043-1048.

Schneider, S. H. 1989. Global Warming. Sierra Club Books, $317 \mathrm{pp}$.

Skidmore, E. L. 1986. Wind erosion climatic erosivity. Climatic Change 9: 195-208.
Spooner, B. 1982. Rethinking desertification: the social dimension, in Desertification and Development: Dryland Ecology and Social Perspective. Edited by B. Spooner and H. S. Mann. Academic Press, New York, 1-24.

United Nations 1978. United Nations Conference on Desertification, Roundup, Plan of Action and Resolutions. United Nations, New York, 43 pp.

UNCOD 1977. Desertification: Its Causes and Consequences. Prepared by the Secretariat of the United Nations Conference on Desertification. Pergamon Press, Oxford, $448 \mathrm{pp}$.

UNESCO 1977. World Map of Arid Regions. United Nations Educational, Scientific and Cultural Organization, Paris.

Verstraete, M. M. 1983. Another look at the concept of desertification. In: S. Wells and D. Haragan (Eds.). Origin and Evolution of Deserts. University of New Mexico Press, Albuquerque, 213-228.

Verstraete, M. M. 1986. Defining desertification: A review. Climatic Change 9: 5-18.

Verstraete, M. M. \& Dickinson, R. E. 1986. Modeling surface processes in atmospheric general circulation models. Annales Geophysicae 4: 357-364.

Verstraete, M. M. \& van Ypersele, J. P. 1986. Wind versus water erosion in the context of desertification. In: Physics of Desertification. Edited by F. El-Baz and M. Hassan. Martinus Nijhoff Publishers, Dordrecht, 35-41.

Verstraete, M. M. \& Pinty, B. 1990. The potential contribution of satellite remote sensing to the understanding of arid lands processes. In this volume.

Warren, A. 1984. The problem of desertification. In: Key Environments: Sahara Desert. Edited by J. L. CloudsleyThompson. Pergamon Press, Oxford, 335-342.

Warren, A. \& Maizels, J. K. 1977. Ecological change and desertification, in Desertification: Its Causes and Consequences. Prepared by the Secretariat of the United Nations Conference on Desertification. Pergamon Press, Oxford, 169-260.

WRI 1986. World Resources 1986. World Resources Institute and International Institute for Environment and Development. Basic Books Inc., New York, 353 pp. 